\title{
ENTRINCHEIRAMENTO ORGANIZACIONAL: A VISÃO DOS SECRETÁRIOS EXECUTIVOS DE UM INSTITUTO FEDERAL DE EDUCAÇÃO.
}

\author{
${ }^{1}$ NOBRE, E.A., OLIVEIRA, F. F. e LEONE, N. M. C. P. G. \\ 1elizomar.nobre@ifrn.edu.br
}

Submetido 19/09/2016 - Aceito 25/08/2017

DOI: $10.15628 /$ holos.2017.5057

\section{RESUMO}

Esta pesquisa procurou analisar o entrincheiramento organizacional na percepção dos secretários executivos numa instituição pública de ensino na cidade de Natal no Rio Grande do Norte, Brasil. Para o desenvolvimento deste estudo, aplicou-se uma pesquisa descritiva e exploratória, aplicada a sete secretários executivos. O trabalho desenvolveu-se a partir da análise de conteúdo de sete entrevistas semiestruturadas em profundidade, numa abordagem qualitativa. Os resultados demonstram que a maioria dos profissionais estão comprometidos com a instituição, uma vez que demonstram estarem satisfeitos com o que fazem e o local no qual desenvolvem suas atividades. No entanto, há servidores insatisfeitos com as atividades que desenvolvem, estão entrincheirados pois nesse momento sair da organização não é vantajoso devido a perdas de estabilidade, salariais e outros benefícios.

PALAVRAS-CHAVE: Carreira; Entrincheiramento; Secretário Executivo.

\section{ORGANIZATIONAL ENTRENCHMENT: THE VISION OF THE EXECUTIVE SECRETARIES OF A FEDERAL INSTITUTE OF EDUCATION.}

\begin{abstract}
This research tried to analyze the organizational entrenchment in the perception of executive secretaries in a public educational institution in the city of Natal in Rio Grande do Norte, Brazil. For the development of this study, a descriptive and exploratory research applied to seven executive secretaries was applied. The work was developed from the content analysis of seven semi-structured interviews in depth, in a qualitative, exploratory and
\end{abstract}

descriptive approach. The results show that most professionals are committed to the institution, since they demonstrate that they are satisfied with what they do and the place where they carry out their activities. However, there are servers who are dissatisfied with the activities they develop, they are entrenched because at that moment, leaving the organization is not advantageous due to losses of stability, salary and other benefits.

KEYWORDS: Carrer, Entrenchment,Eexecutive Secretary 


\section{INTRODUÇÃO}

A importância do trabalho na vida do ser humano tem sido evidenciada no desenvolvimento do mesmo na prática transformadora da realidade que viabiliza a sobrevivência e a realização do ser humano. A carreira por sua vez é uma trajetória de mudanças para níveis de maior complexidade ao longo da vida profissional. A qualidade do vínculo do indivíduo com a carreira é relevante no sentido do compartilhamento de valores atitudinais e a cultura organizacional da instituição, esse relacionamento torna-se vulnerável e para o indivíduo fica a sensação de não ter outra alternativa, há tendência do profissional continuar na organização devido a permanência por necessidade. A definição do conceito entrincheiramento, originado nas trincheiras, que sugere um local de proteção e segurança, é um tema relativamente recente onde é definido como uma tendência de o indivíduo permanecer em sua carreira devido aos investimentos feitos, aos custos emocionais e a percepção de poucas alternativas. Na visão de Schein (1990), as transformações no mundo de trabalho e das organizações não permitem uma previsibilidade ou probabilidade de transições inesperadas.

Pensar em carreira consiste em analisar objetivos pessoais e profissionais, de acordo com Fernandes (2013), com o passar dos anos, as instituições e seus colaboradores vêm se adaptando as transformações globais frente ao dinamismo da evolução do mundo decorrente das necessidades de suprir as novas demandas institucionais e das pessoas que ali investem na carreira profissional. A carreira é considerada uma trajetória de mudanças para níveis de maior complexidade ao longo da vida profissional.

Segundo Klein (2016) é importante compreender quais fatores afetam a satisfação da carreira, e potencializam a evasão e a insatisfação em alguns casos, causando efeitos variáveis os quais mostram que fatores extrínsecos como remuneração e intrínsecos como a natureza do trabalho. Estes fatores influenciam diretamente na motivação profissional, podendo causar alta taxa de rotatividade e evasão das profissões.

Diante das dificuldades associadas à empregabilidade e à instabilidade do mercado, é possível que a permanência numa carreira seja mais determinada pela insegurança associada à construção de novas alternativas do que propriamente de uma forte identificação e forte vínculo afetivo com a carreira já construída, conforme a visão de Rowe et al. (2011).

A medida que o profissional está satisfeito com sua carreira e com a organização em que está desenvolvendo suas atividades, o vínculo com a mesma tende a ter uma qualidade melhor, pois haverá um compartilhamento entre os valores do indivíduo com a carreira e a cultura organizacional da instituição. Se essa troca é feita de maneira comprometida, tanto ganha o indivíduo como a organização. Porém quando não existe por parte de ambos uma relação positiva, e as expectativas tanto do profissional quanto da instituição não são concretizadas, esse relacionamento torna-se vulnerável, assim para o indivíduo fica a sensação de não ter outra alternativa.

O profissional percebe que está na organização não porque gosta de estar, mas porque sente que terá grandes perdas se deixá-la. Há custos na sua saída e, portanto, para ele, não há outra saída a não ser permanecer nela. Essa postura estática reflete o estado entrincheirado que ele se encontra, em que o desejo confronta com a necessidade que o profissional tem de permanecer parado, sem motivação.

O conceito de entrincheiramento como um processo de estagnação no qual os indivíduos não se adaptam e não se motivam a encontrar alternativas para seu encaminhamento profissional. 
Partindo dessa premissa, o presente artigo tem como objetivo analisar o entrincheiramento organizacional na perspectiva dos secretários executivos de um instituto de ensino federal de educação na cidade do Natal, Rio Grande do Norte, Brasil. O secretário executivo tem em suas competências a função de assessorar direções, gerenciar informações, executar tarefas administrativas, reuniões; coordenar equipes e atividades; controlar documentos e correspondências; atender usuários externos e internos; organizar eventos e viagens e prestar serviços em idioma estrangeiro. Além do perfil técnico espera-se que o profissional desenvolva habilidades de liderança, iniciativa, foco, conhecimento da organização, capacidade de comunicação e relacionamento interpessoal. Esse profissional que tem a função de assessor a chefia, deve desenvolver comportamento assertivo, proativo, resiliente e efetivo, contribuindo na resolução de problemas em conjunto com sua chefia. (NOBRE, 2013).

\section{CARREIRA}

Na visão de Hall (2002), a carreira profissional é uma sequência de atitudes e comportamentos, associados a experiência e atividades relacionadas ao trabalho, durante o período de vida de uma pessoa. Já para London e Stumph (1982), são sequências de posições ocupadas e trabalhos realizados durante a vida de uma pessoa. Enquanto Dutra (2009) firma que a diferença entre os conceitos está apenas na série de estágios e ocorrências de transições das necessidades de cada indivíduo.

Parafraseando Evans (1996) o indivíduo buscava em seu trabalho o dever e a obrigatoriedade de sustentar sua família e o dever com sua empresa. Este profissional não buscava uma realização profissional e o sentido de dever e obrigação era enraizado. Para o autor, atualmente há uma nova ética baseada no divertimento e na eficiência com profissionais envolvidos que gostam do que fazem, que se engajam nas diversas atividades desenvolvidas na organização, com autonomia diferente da autoridade anteriormente imposta.

Para Blau (2001), carreira representa o padrão de experiências relacionadas ao trabalho de um indivíduo por toda a sua vida. Já Meyer, J. P. e Allen, N. J. A (1991) afirmam ser ocupação o termo mais apropriado, e que se refere a um grupo de pessoas que se considera engajado em algum tipo de trabalho.

Segundo a perspectiva de Rowe, Bastos e Pinho, A. P. M (2011) o indivíduo apresentará o mais alto nível de intenção de deixar a carreira quando houver o nível mais baixo de comprometimento com a mesma, o menor tempo na carreira e a menor experiência educacional. Por outro lado, profissionais entrincheirados e satisfeitos tendem a contribuir construtivamente, reduzindo a rotatividade e aumentando a estabilidade da força de trabalho (CARSON; CARSON, 1997).

\section{SECRETARIADO EXECUTIVO}

A profissão de secretário executivo tem evoluído nos últimos dezesseis anos (NOBRE,2013), passando de uma profissão que apenas executava tarefas simples como datilografia, arquivo e atendimento ao cliente interno e externo, para hoje desenvolver outras competências inclusive gerenciais. De acordo com Veiga (2007) por causa do downsizing que resultou na eliminação de alguns cargos e redução de níveis hierárquicos, com a nova estruturação as atividades que eram exercidas pela gerência passaram a ser incorporada pelos secretários, conforme figura 1.

Diante desse novo perfil profissional o secretário passou a desenvolver outras 
competências, se tornando mais envolvidos no trabalho, capazes de liderar e assessorar o gestor com proatividade, assertividade, eficiência, capacidade de liderança, comunicação e relacionamento interpessoal. (NOBRE, 2013).

O secretário proativo é aquele que possui a capacidade de se antecipar aos acontecimentos, tomar iniciativa. Segundo Covey (2002) a proatividade é motivada pela liderança onde líder e liderados compartilham objetivos comuns, baseados na lealdade, ética e compromisso de querer fazer as coisas certas. Esse poder, que para o autor é positivo, traduz-se numa troca onde o indivíduo é agente de mudança e passam a ter uma postura ativa e não reativa. Nesse sentido os proativos antecipam as ações para resolução de problemas, tornandose ativos dentro do seu ambiente de trabalho, diferente do profissional reativo, que, após surgir algum problema ou desafio, ele apenas reage aos resultados, positivos ou negativos.

Assertivo, conforme Alberti e Emmons (1973) é o profissional que possui uma atitude positiva diante das situações vividas, é transparente e bom ouvinte. Tais características têm sido um diferencial para esses profissionais que diariamente enfrenta diversas situações de estresse.

Outra característica é a eficiência diante de todas as decisões que precisa tomar no dia a dia, é usar os meios de forma correta, eficaz gerando resultados positivos. Pode-se dizer que é a pretensão de alcance dos resultados com eficácia.

Diante das pressões do dia a dia, a busca de um equilíbrio no cotidiano dos profissionais de secretariado tem sido uma busca diária, segunda Maerker (2008). Na opinião da autora, atualmente o profissional que possua o conhecimento técnico necessário, domínio de tecnologias que venham agregar ao desenvolvimento do seu trabalho, fluência em idioma estrangeiro é relevante para quem deseja manter seu emprego e ser reconhecido. Porém sem o amadurecimento emocional, esse profissional não conseguiria tornar-se esse profissional efetivo e competente.

As competências emocionais são relevantes no dia a dia desses profissionais que necessitam dessas ferramentas complementares para auxiliar em sua rotina. Gerir diversas atividades, tomar decisões, desenvolver o relacionamento interpessoal, pois esse profissional possui como principal competência assessorar o gestor da instituição ou organização que trabalha. (MAERKER, 2008).

Veiga (2007) diz que para ser um profissional de secretariado não é necessário apenas habilidades técnicas, competências e conhecimento. Para exercer o cargo é necessário ter competência específica na área de secretariado. Conforme esse mesmo autor, ser secretária não é para quem quer, é para quem tem capacidade para exercer a profissão com eficiência e eficácia.

\section{ENTRINCHEIRAMENTO}

O entrincheiramento vem sendo pesquisado por vários autores (CARSON; CARSON(1997); MAGALHÃES; GOMES (2005); RODRIGUES (2009); PINHO et al. (2010); ROWE et al. (2011); PASSOS (2012); SCHEIBLE; BASTOS (2013)), como a tendência para manter seu vínculo empregatício por causa de investimentos, preservação psicológica, e uma percepção de que há poucas oportunidades de carreira no mercado de trabalho, é considerado como uma metáfora que remete à continuidade de profissionais em uma carreira, porque mudar lhes parece desvantajoso ou inviável.

O conceito de entrincheiramento surgiu há aproximadamente 20 anos com os estudos de Carson e Carson (1997). A definição utilizada pelos autores é a tendência de o indivíduo permanecer na profissão por falta de opções de mudanças, falta de alternativas e até 
investimentos feitos na carreira. Essa percepção inicia com a escolha da profissão, sua avaliação como instrumentos de alcance de metas e oportunidades de carreira, pois na medida que investe em sua carreira há uma avaliação como o alcance de metas e objetivos pessoais.

O termo entrincheiramento que é utilizado como metáfora, remete à ideia de que para o trabalhador de uma organização, mudar de carreira pareça desvantajoso, por isso eles ficam presos em suas trincheiras, ou seja suas carreiras, para Silva, Lima e Leone (2015). A ideia de estar entrincheirado pode incluir o desejo de evitar estigma social, receio que a idade seja limite para recolocação no mercado ou mesmo o medo de perder privilégios já adquiridos no decorrer nos anos.

Para Rodrigues (2009), quanto maior o estigma associado ao seu afastamento, status alcançado, limitação de empregabilidade e ceticismos sobre ganhos financeiros, mais entrincheirado o indivíduo está. Carson e Carson (1997) propõem como modelos o investimento na carreira, ou seja, os investimentos acumulados tais como dinheiro, esforço e tempo dedicado. Outro modelo são os custos emocionais que está associado à mudança, interrupções de relacionamentos interpessoais e perda de conhecimento social. As limitações das alternativas, pela percepção de poucas oportunidades fora da carreira é outro ponto defendido pelos autores. Segundo ele, os profissionais entrincheirados tendem a terem menor intenção de afastamento e maior estabilidade em comparação aos não entrincheirados. São indivíduos que sentem que perderão se deixarem suas atuais ocupações, por isso se sentem protegidos, porém não estão motivados.

Na percepção de Magalhães e Gomes (2005), os profissionais entrincheirados, não estão preocupados com sua produtividade, nem engajados na possibilidade de contribuir. $O$ estudo desenvolvido pelos autores propõe a explicação de que o trabalhador não busca destaque ou melhores resultados.

Para o entrincheiramento organizacional, Rodrigues e Bastos (2013) propõem três dimensões, tais como:

1. Ajustamento à Posição Social (APS), onde o indivíduo faz investimentos como treinamentos, tempo para conhecer os processos organizacionais, construção de relacionamentos com os colegas.

2. Arranjos Burocráticos Impessoais $(A B I)$, quando há o temor de perder a estabilidade adquirida além dos benefícios conquistados ao longo dos anos.

3. Limitações de Alternativas (LA), referindo-se a percepção de falta de alternativas, caso saia da organização, por considerar que idade desfavorece a reinserção ou seus conhecimentos não são suficientes para atuar em outra organização.

No construto entrincheiramento organizacional, há um entendimento por Rodrigues (2009) que este termo vem de trincheiras, abrigos utilizados principalmente depois da Segunda Guerra Mundial, termo associado a proteção e estratégias, pois remete a ideia de segurança. Transpondo o termo para o contexto organizacional, há uma percepção que se trata de forma de proteção, garantias de estabilidade, manutenção do seu status quo, fazendo que o vínculo do indivíduo com a organização seja por necessidade e não por desejo. Para o profissional é mais vantajoso permanecer pois sua saída pode acarretar perdas consideráveis.

Rodrigues ainda explica que a teoria da dissonância cognitiva de Festinger (1975) mostra que o indivíduo se esforça para atingir a coerência consigo mesmo, principalmente quando confrontado por dois elementos dissonantes, há uma tendência de buscar consonância, sabendo que para o profissional entrincheirado a tendência de ficar na organização é mais coerente que a 
vontade de sair dela, para isso adotará medidas para evitar dissonâncias futuras. Ele complementa que um exemplo prático dessa situação é o profissional que não procura novas oportunidades, não busca recolocação no mercado, não distribui currículos, pois para ele é mais vantajoso permanecer aonde está até sua aposentadoria.

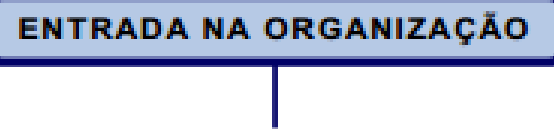

Periodo de adaptaçāo

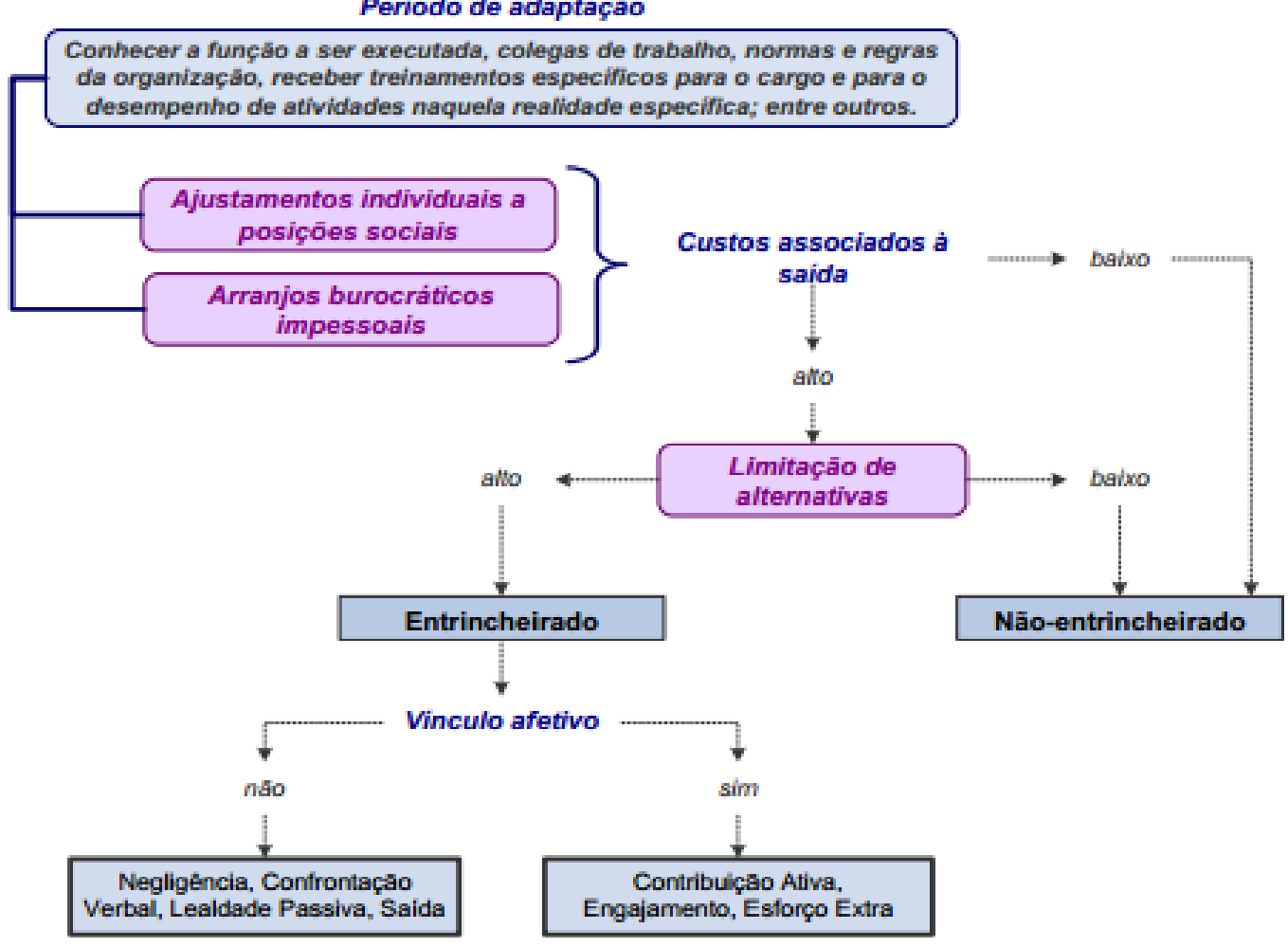

Figura 2: Modelo de entrincheiramento na organização

FONTE: Adaptado do modelo de entrincheiramento na carreira (Carson e Carson, 1997)

O entrincheiramento na perspectiva de Carson e Carson (1997) mostra que para os profissionais insatisfeitos há uma tendência em buscar mecanismos como absenteísmo, aumento de erros no trabalho e ineficiência, não há um esforço dos mesmos em buscar a excelência, o aprimoramento contínuo para conquistar novos espaços na organização.

Numa perspectiva mais ampla Rodrigues (2009) enfatiza que o conceito de entrincheiramento tanto na carreira quanto na organização, o vínculo desenvolvido pelo indivíduo o mantém preso como uma trincheira, por não conseguir visualizar alternativas que o incentive de acordo com suas expectativas.

De acordo com a perspectiva de Carson e Carson (1997), as reações do profissional entrincheirado estão ligadas ao seu grau de satisfação, podendo ser indivíduos entrincheirados satisfeitos e insatisfeitos. Os primeiros correspondem os profissionais que tendem a contribuir construtivamente, reduzindo a rotatividade e aumentando a estabilidade do trabalho e são normalmente, engajados. Os entrincheirados insatisfeitos estão relacionados a uma lealdade passiva podendo gerar absenteísmo, normalmente criam mecanismos de gerenciamento de estresse. A alternativa para tal comportamento é que eles estão na organização não porque querem estar, mas por necessitarem, pois, sua saída poderá causar prejuízos. Em ambos os 
casos, é importante salientar que o entrincheiramento é a essência do vínculo desenvolvido pelo indivíduo que o mantém preso por não visualizar alternativas que o sustente de acordo com suas necessidades e expectativas. Dessa forma, a sua permanência não é espontânea, mas por perceber que é necessário ficar.

\section{METODOLOGIA}

Para investigar o entrincheiramento organizacional na perspectiva dos secretários executivos de um instituto de ensino federal de educação na cidade do Natal no Rio Grande do Norte, Brasil. Esta pesquisa utiliza abordagem qualitativa, sendo os sujeitos desta pesquisa sete profissionais de carreira ocupantes dos cargos de secretário executivo da instituição federal de ensino. A pesquisa tem caráter descritivo por entender e explicar os fenômenos (VERGARA 1998).

O embasamento teórico e conceitual foi alcançado através de uma pesquisa bibliográfica onde foi fundamentado nos estudos sobre Carreira (Evans, 1996; Shein, 1990; Fernandes, 2013; Klein, 2016; Hall, 2002; London e Stumph, 1982, Dutra, 2002; Blau, 2001; Meyer e Allen, 1991); Secretariado Executivo (Alberti e Emmons, 1973; Covey, 2009; Maerker, 2008; Nobre, 2013; Veiga, 2007); Entrincheiramento de Carreira (Carson e Carson, 1997; Rodrigues, 2009; Magalhães e Gomes, 2005;) Entrincheiramento Organizacional (Rodrigues e Bastos, 2013; Silva, Lima e Leone, 2016).

Para a coleta de dados foi utilizado como instrumento de pesquisa uma entrevista composta de duas partes: a primeira contendo questões referentes à identificação dos secretários executivos, cujo intuito é categorizar os entrevistados. A segunda parte, foi uma entrevista semiestruturada, na qual o roteiro elaborado foi direcionado as três dimensões do entrincheiramento organizacional proposto por Rodrigues e Bastos (2012) - Ajustamentos à Posição, Arranjos Burocráticos Impessoais e Limitações de Alternativas. As entrevistas foram realizadas no local de trabalho dos pesquisados, com duração de 15 minutos cada, durante o mês de maio de 2016.

Inicialmente houve uma rápida apresentação pessoal, histórico e objetivo da pesquisa com a garantia do sigilo de dados. As entrevistas não foram gravadas, utilizando-se tablet para anotação das mesmas para posterior análise.

Os dados foram tratados e submetidos à análise de conteúdo, que segundo Bardin (1995) "aparece como um conjunto de técnicas de análise de comunicações, que utiliza procedimentos sistemáticos e objetivos de descrição do conteúdo de mensagens". A análise se deu através da transcrição das entrevistas que constituiu o corpo do estudo, a edição e a inferência das mesmas.

Foram nomeados nessa pesquisa desta forma: Entrevistado 1 (E1), Entrevistado 2 (E2), Entrevistado 3 (E3), Entrevistado 4 (E4), Entrevistado 5 (E5), Entrevistado 6 (E6) e Entrevistado 7 (E7). Foram escolhidos esses profissionais pelas suas competências na função de assessorar direções, gerenciar informações, executar tarefas administrativas, coordenar equipes e atividades.

A viabilidade desse estudo se dá pela importância que esses profissionais têm, como podem auxiliar a instituição na compreensão do que é o entrincheiramento, sua influência no desempenho de tais profissionais dentro do ambiente de trabalho e na busca de mecanismos para torná-los comprometidos e motivados. 


\section{ANÁLISE E DISCUSSÃO DOS RESULTADOS}

A pesquisa foi desenvolvida numa instituição federal de ensino que traz consigo a imagem de uma organização sólida e consolidada com 106 anos. Foram aplicadas entrevistas semiestruturadas aos servidores secretários executivos no total de sete entrevistas, por meio do qual buscou-se analisar o entrincheiramento organizacional na perspectiva desses profissionais. $\mathrm{Na}$ totalidade foram entrevistados $40 \%$ dos servidores do cargo de secretário executivo cujo critério foi acessibilidade e disponibilidade.

Os entrevistados trabalhavam pelo menos três anos na organização. Alguns tinham formação na área outros não, pois o requisito para investidura no cargo era graduação em secretariado e letras. Quase todos dos profissionais com formação em secretariado e letras, possuem especialização, a média da idade dos inquiridos entrevistados foi de 40 anos e a grande maioria do gênero feminino.

Todos os entrevistados desconheciam o construto entrincheiramento, após explicação do que significa e quais características, alguns se identificaram com o conceito. Após análise das respostas é possível identificar que para alguns entrevistados há um nível grande de satisfação das atividades desempenhadas na organização não demonstrando nenhum interesse em mudar de instituição ou de local de trabalho. Há também os que gostam do que fazem, porém, se houvessem outras oportunidades, trocariam para uma de melhores condições. Também foi apontado a não identificação com o cargo e a instituição.

É percebido que na sua maioria a instituição foi escolhida pela oportunidade de uma carreira estável e bem remunerada proporcionado pelo concurso público além de boas condições de trabalho e benefícios atrativos.

\subsection{Ajustamento à Posição}

Todos os entrevistados entraram na instituição através de concurso público e exercem o mesmo cargo. Para dar início às atividades foi necessário um aprimoramento através de cursos de capacitação. Para a maioria, a busca de aperfeiçoamento para melhor desempenhar as funções do cargo foi crucial. Nesse contexto, alguns entrevistados preferiram fazer cursos da área de secretariado ou por não ter a formação específica ou por querer se aperfeiçoar no cargo. Outros preferiram investir em cursos mais específicos que os habilitariam a desenvolver determinadas tarefas no setor que trabalha.

Também houve aquele que preferiu fazer cursos que agregasse, trouxesse algo novo para seu desenvolvimento na instituição, não sendo necessariamente ligada ao cargo. Também há caso do que investiu em capacitação com um olhar para a gestão. No modo geral, todos, em certo momento, investiram em capacitação. A instituição custeou cursos, treinamentos, congressos, seminários. A sua maioria está disposto a novas qualificações, como exemplo muitos estão buscando o mestrado para melhorar a sua trajetória dentro da organização.

Para o entrevistado E2, é importante a busca de aperfeiçoamento, principalmente em cursos que agreguem ao cargo, por isso aproveita para fazer cursos inclusive de gestão para dar um olhar diferente e buscar crescimento profissional. Na visão de E2 "Os gestores enxergam o que você faz, e também pelo que você se capacita", Para E1 foi muito importante o curso de capacitação feito inicialmente quando entrou na instituição, para ele: "O curso foi bem conveniente, uma vez que situou algumas rotinas de trabalho e atividades que iriamos desempenhar, em conformidade com a função social da instituição. O curso além de informativo, também serviu para integrar a equipe de secretários". O entrevistado não fez muitos cursos, 
porém prefere capacitar-se com mais profundidade nos cursos de incentivo à qualificação que a instituição oferece.

Nesse aspecto E3 tem praticamente a mesma opinião de E1 pois preferiu investir em cursos de graduação, especialização e busca o mestrado. Para E4 o mais importante é fazer cursos que pareçam diferentes aos da área, mas que lhe dão uma visão diferente e mais ampla, por isso investiu em cursos não específicos, porém que agregassem valor. Também participou de congresso na área de secretariado. E5 diz que procurou aperfeiçoar-se em todo o período que esteve na organização, investindo em sua carreira, já para E6 poucos foram os investimentos, apenas o curso inicial, os cursos para progressão e por fim participação em congressos. Para E7 que fez cursos de especialização na área secretarial pois sua formação é diferente do cargo desenvolvido, acha primordial a busca de aperfeiçoamento e também procura fazer mestrado na área.

No que diz respeito ao relacionamento pessoal nenhum deles demonstrou que a amizade é suficiente o bastante para influenciarem mudança de organização ou mesmo de setor. Todos foram unânimes em dizer que no dia a dia, o desenvolvimento profissional não está diretamente relacionado a relação interpessoal embora esta deva ser importante para o desenvolvimento de um trabalho. Alguns dos entrevistados demonstrou que o desempenho de um bom trabalho permite que haja um relacionamento interpessoal positivo e produtivo. Para E1:

"Há uma relação mútua com valores e objetivos comuns. Claro que com algumas exceções. Mas, acho que, no geral, as pessoas aqui são defensoras do bem público, trabalham com zelo e dedicação. Com isso, me sinto bem fazendo o que faço e importante para a sociedade. Sei que meu trabalho reflete em vários outros dentro e fora da instituição. E se trabalhamos em rede, atingiremos os objetivos institucionais mais facilmente e com melhor qualidade".

A maioria disse sentir-se realizado com o que faz, ser secretários para eles é um desafio que adoram fazer, outros nem tanto. Há uma identificação com a organização, com os valores, com a história e não se vêm em outro ambiente que não esse. Outros demonstraram que gostam da instituição, porém trocariam se houvesse oportunidades melhores. Alguns ainda procuram conquistar alguns benefícios que perderam ao longo do tempo na organização e isso faz diferença na maneira como enxergam a mesma. De certa forma acham que podem conquistar algo melhor fora da instituição.

Analisando as respostas percebe-se que parte dos entrevistados está distanciada do fenômeno entre a dimensão Ajustes à Posição (Rodrigues e Bastos, 2012) pois alguns estão dispostos a trocarem os investimentos realizados, bem como o status, o relacionamento construído com os colegas e o reconhecimento adquirido para recomeçar em outra instituição e até mesmo em outra profissão.

\subsection{Arranjos Burocráticos Impessoais}

O fato do profissional temer em perder a estabilidade adquirida, caso mude de área e atividade profissional, afirmaram Rodrigues e Bastos (2012), foi percebido por alguns dos entrevistados que trocariam de instituição. De acordo com os entrevistados a instituição oferece estabilidade, segurança, salários, plano de carreira, plano de saúde além de um grande incentivo a capacitação, e isso é um diferencial para que não troquem de organização pelos benefícios adquiridos. Para poucos isso não é um empecilho e se houvesse outra oportunidade sairiam da organização. Nesse caso afirmam que os benefícios concedidos pela instituição não são fatores determinantes para a permanência na mesma, o que vai contra os sintomas de um profissional entrincheirado. 
Por outro lado, o entrevistado E6 diz que, neste momento, a instituição é a melhor opção, porém não tem vontade de buscar outras oportunidades, mas que não está totalmente satisfeito com a mesma, demonstrando assim um sintoma de profissional entrincheirado.

Para os que não trocam de instituição por sentirem-se realizados, se sentem motivados, e enxergarem que na organização em que trabalham há oportunidades de crescimento, também não é identificado um sintoma de entrincheiramento, pois segundo Rodrigues e Bastos (2012) o entrincheiramento é para aqueles que sentem que perdem os investimentos realizados, mas que não sentem desejo de se manter nela e sim uma necessidade.

\subsection{Limitação de Alternativas}

Ao se tratar da dimensão de limitação de alternativas, todos os entrevistados são unânimes em achar que o concurso dá uma estabilidade e segurança que as empresas privadas não podem oferecer, então nenhum deles demonstrou interesse em sair da organização para empresas privadas. Entretanto alguns entrevistados não apresentaram dificuldade ou medo de enfrentar outros desafios ao realizarem outros concursos para instituições onde o salário, os benefícios e o seu desenvolvimento como profissional seja melhor do que na instituição que estão.

Outros ainda não tem o menor interesse em mudar de organização ou fazer outros concursos, por estarem plenamente realizados aonde estão ou por acharem que não há mais tempo para recomeçar.

Para o entrevistado E6 nesse momento a melhor opção é ficar pois, mesmo que não esteja plenamente satisfeito, não sente vontade em voltar, nesse momento, a estudar para concursos. As afirmações feitas pelo entrevistado E6 demonstram que este é o comportamento de um profissional entrincheirado e insatisfeito com o trabalho.

Segundo Carson e Carson (1997) há uma tendência dos profissionais entrincheirados em buscar mecanismos de gerenciamento de estresse, como confrontação verbal, lealdade passiva, ou negligência que inclui absenteísmo, falta de interesse em buscar crescimento na instituição que desenvolve suas atividades.

\subsection{Entrincheiramento e Satisfação na Carreira}

Analisando as entrevistas percebeu-se que a maioria dos entrevistados estão comprometidos ou motivados pois se sentem realizados na organização e outra parte, entrincheirados, por desejarem mudanças, mas no momento está na organização por necessidade e não por vontade. Percebeu-se também que há profissionais que, embora satisfeitos com a organização, apresentam sintomas de entrincheiramento. Estes profissionais que são entrincheirados e satisfeitos contribuem positivamente na organização por reduzir a rotatividade aumentando a estabilidade da força de trabalho, conforme Carson e Carson (1997) afirmam.

Segundo os autores, nem sempre os profissionais entrincheirados apresentam consequências disfuncionais por não estar satisfeitos com sua situação, os autores apontam que uma possível solução para esses casos seriam os servidores fazerem as pazes com sua própria carreira enraizada ou mudar de local de trabalho poderá a ajudá-los o desenvolvimento pessoal e profissional. 


\section{CONSIDERAÇÕES FINAIS}

O presente estudo teve como objetivo analisar o entrincheiramento organizacional na percepção dos secretários executivos de uma instituição federal de ensino em Natal/RN. O modelo que foi proposto foi o utilizado por Rodrigues e Bastos (2012) que propõe três dimensões para o entrincheiramento organizacional baseados nos estudos de Becker (1960): Ajustamento à posição social (APS), Arranjos burocráticos impessoais (ABI) e Limitação de alternativas (LA).

Em referência a dimensão de Ajustamento à Posição Social pode-se considerar que na sua maioria os respondentes afirmaram se tratar de uma boa organização que oferece estabilidade, segurança, bom salário, benefícios como plano de saúde, plano de cargo e salários e incentivo a capacitação dos servidores. Alguns demonstraram que por mais que tenham investido tempo em capacitações, treinamento, cursos além do relacionamento pessoal criando vínculos no ambiente de trabalho, nada disso impossibilitaria de os fazer mudar de organização, caso surgisse oportunidade. Outros relataram que de forma nenhuma mudaria de organização, porém não por causa dos investimentos ou do relacionamento pessoal, mas por terem criado vínculo afetivo com a organização.

No parâmetro Arranjos Burocráticos Impessoais ( $A B \mathrm{~B})$, os resultados mostram que, para os entrevistados, a instituição é uma organização sólida renomada, onde oferece vantagens e incentivos a formação de profissionais e isso é um diferencial da organização. Alguns dos entrevistados dizem gostar da organização, mas trocaria assim que tivessem oportunidade, não demonstrando entrincheiramento. Alguns dos respondentes que apresentaram temor em sair da organização pela perda dos benefícios e não estarem dispostos em voltar a recomeçar, mostrando que podem estar entrincheirados à instituição.

Na dimensão Limitação de Alternativas a maioria dos entrevistados não deseja trocar de organização pois consideram ser a organização mais atrativa em referência a outras organizações públicas. Alguns respondentes dizem não ter o menor problema em mudar de instituição tendo em vista alcançar oportunidades diferentes, porém não o fazem por que a situação atual é mais vantajosa, demonstraram claramente estarem entrincheirados e insatisfeitos com a instituição.

Foi percebido limitações no decorrer da pesquisa, por não poder ser possível entrevistar todos os servidores do cargo, tendo em vista, distância ou pelo fato de os profissionais estarem ocupados e não estarem disponíveis.

Sugere-se que esta pesquisa possa ter um foco mais ampliado, e que se estenda a profissionais de outras áreas. Espera-se que através desse trabalho se construa futuras investigações sobre o vínculo do indivíduo e a organização e que o construto entrincheiramento organizacional se desenvolva na pesquisa teórica e empírica, contribuindo para o avanço das investigações e ajudando a delimitar o conceito de comprometimento organizacional.

\section{REFERÊNCIAS}

ALBERTI, R. E.; EMMONS, M. L. (1973). Comportamento Assertivo: um guia de auto-expressão. Tradução: Jane Maria Correia. Califórnia, 147 p.

BARDIN, Laurence. ( 1995). Análise de Conteúdo. Edições 70, LDA. Lisboa, tradução.

BLAU, G. (2001). On assessing the constructo validity of two multidimensional constructs Occupational commitment and occupational entrenchment. Human Resource Management Review. Philadelphia, PA, p. 279-298. 
CARSON, K.D, \& CARSON, P. P. (1997). Career Entrenchment: A quiet march toward occupational death? Academy of management executive, p. 62-75.

COVEY, S.R. (2006). Liderança baseada em princípios. Rio de Janeiro: Elsevier.

DUTRA, J. S. (2009). Gestão de pessoas: modelo, processos, tendências e perspectivas. 1 ed. São Paulo: Atlas.

EVANS, Paul. (1996). Carreira, Sucesso e Qualidade de Vida. Revista de Administração de Empresas, ERA. São Paulo, pp. 14-22.

FERNANDES, Bruno. (2013). Gestão Estratégica de Pessoas com foco em competências. Rio de Janeiro: Elsevier Editora Ltda, Cap. 7, pp. 139-168.

FESTINGER, L. (1975). Teoria da dissonância cognitiva. Rio de Janeiro: Zahar Editores.

HALL, D. T. (2002). Careers in and out of organizations. Thousand Oaks: Sage Publications, Inc., 368 p. (Foundations for Organizational Science).

KLEIN, F, A. (2016). Motivação, Satisfação Profissional e Evasão no Serviço Público: o caso da carreira de especialistas em Políticas Públicas e Gestão Governamental. Revista Administração Pública. Rio de Janeiro. pp. 17-39.

LONDON, M.; STUMPH, S. (1982). Managing careers. Massachusetts: Addison Wesley.

MAERKER, S. (2008). Secretária: uma parceira de sucesso. São Paulo: Infinito, 119p.

MAGALHÃES, M. O., \& GOMES, W. B. (2005). Personalidades vocacionais, generatividade e carreira na vida adulta. Revista Brasileira de Orientação Profissional, n. 6, p. 71-79.

MEYER, J. P., \& ALLEN, N. J. A (1991). Three-Component Conceptualization of Organizational Commitment. Human Resource Management Review, Ontário, Canadá. v. 1, n. 1, p. 61-89.

NOBRE, E. A. (2013). Inteligência Emocional: um diferencial para o profissional de secretariado executivo. Expectativa, v. XII, no 12, p. 43-54.

PASSOS, E.O. (2012). Entrincheiramento e Comprometimento com a Carreira Profissional entre Empregados Públicos: o caso de um órgão do poder judiciário federal brasileiro. Dissertação de Mestrado da Universidade Católica de Brasília, Pós Graduação em Psicologia, Brasília.

PATTON, M. G. (2002). Qualitative Research and Evaluation Methods, 3 ed. Thousand Oaks,

CA: Sage.

PINHO, A.P.M., BASTOS, A.V.B., ROWE, D.E.O. (2010). Comprometimento, Entrincheiramento e Consentimento Organizacionais: o conceito desses vínculos entre gestores que atuam em diferentes organizações. 13 Entrincheiramento organizacional. In: VI Encontro de Estudos Organizacionais da ANPAD. Florianópolis. Anais. Florianópolis. 
RODRIGUES, A. C. A. (2009). Do comprometimento de continuação ao entrincheiramento organizacional: o percurso de validação da escala e análise da sobreposição entre os construtos. Dissertação de mestrado. Universidade Federal da Bahia, Bahia.

RODRIGUES, A. P. G; BASTOS, A. V. B. (2013). Os vínculos de Comprometimento e Entrincheiramento Presentes nas Organizações Públicas. Revista de Ciências da Administração. Santa Catarina, p. 143-158.

RORIGUES, A. C. A., \& BASTOS, A. V. B. (2010). Problemas conceituais e empíricos na pesquisa sobre comprometimento organizacional: uma análise crítica dos modelos trimendisional de J. Meyer e N. Allen. Revista de Psicologia Organizacional e do Trabalho, v. 10 n. 2, p. 129-144.

ROWE, D. E. O., BASTOS, A. V. B., \& PINHO, A. P. M (2011). Comprometimento e entrincheiramento na carreira: um estudo de suas influências no esforço instrucional do docente do ensino superior. Revista de Administração Contemporânea. Curitiba, v. 15, n. 6, 2011. Disponível em: http://www.scielo.br/scielo.php?script=sci arttext\&pid= $=$ S141565552011000600002 Acesso em: 1 mai. 2016.

SCHEIBLE, A. C. F., \& BASTOS, A. V. B. (2013) An examination of human resource management practices' influence on Organizational Commitment and Entrenchment. BAR, Brazilian Administration Review. Rio de Janeiro, v. 10, n. 1, mar. Disponível em $<$ http://www.scielo.br/scielo.php?script=sci_arttext\&pid=S180776922013000100005\&lng=p t\&nrm=iso>. Acesso em: 01 mai. 2016. Epub 27-Nov 2012.

SCHEIN, Edgar H. (1990). Organizational Culture. American Psychologist. Vol. 45(2), p. 109-119.

SILVA, P. M. M; LIMA, A. N. C.; LEONE, N. M. C. P. G. (2015). Entrincheiramento Organizacional: percepção de empregados de uma agência bancária. Revista de Administração - IMED, v. 5 no 2, p. 111-120.

VEIGA, D.R. (2007). Guia de Secretariado: Técnicas e Comportamento. 3ạ Edição. Nacional Editora, 160

p.

VERGARA, S. C. (1998). Projetos e relatórios de pesquisa em administração. 2ạ. ed. São Paulo:

Atlas. 